\title{
ANÁLISE DA DUREZA VICKERS DA SUPERFÍCIE DE DENTES ARTIFICIAIS EM RESINA POLIÉSTER
}

\section{VICKERS HARDNESS LABORATORY ANALYSIS SURFACE OF ARTIFICIAL TEETH RESIN}

\author{
João Marcelo Ferreira de Medeiros* \\ Gabriela dos Santos Ferreira* \\ Sandra Marcia Habitante**. \\ Christian Frederico de Avila Von Dollinger"**** \\ Adriano Albano Forghieri***** \\ Miguel Simão Haddad Filho
}

\section{RESUMO}

Avaliou-se a microdureza Vickers de 5 dentes artificiais de resina contendo canais simulados e câmara pulpar $(17,21,24,33$ e 44) valendo-se de microdurômetro.Os dentes foram acondicionados em embutidora metalográfica, sendo adicionada resina fenól-aldeído de cura a quente e que por efeito de temperatura e pressão ocorre à fusão do pó de resina fenólica e a cura da resina resulta em corpo de prova com o dente embutido. Após isso, lixado e polido e levados a um suporte para fixação dos mesmos na plataforma na base do equipamento. A seguir, realizou-se os ensaios da dureza Vickers (HV) em cada um dos 5 dentes embutidos valendo-se de microdurômetro equipado por uma base, penetrador com carga de 100gf que entrava em 5 pontos aleatoriamente escolhidos na superfície do dente durante 15 segundos. Posteriormente as leituras cujo valor numérico foram calculado no visor digital conectado no microscópio. As endentações são deixadas na superfície da amostra sob a forma de losango regular cujas diagonais foram medidas. Não ocorreu diferença estatisticamente significante entre os valores das médias das amostras dos dentes artificiais em resina de poliéster testados, o que significa que na média dos 5 pontos de cada amostra as durezas são equivalentes ( $p>0,05$ ), exceção feita entre os dentes $17 \times 21$ e do $17 \times 44(p<0,05)$. Concluiu-se que, a média dos valores dos dentes artificiais de resina poliéster apresentou dureza Vickers equivalentes, exceção feita entre dois pares de amostras dos dentes artificiais que apresentaram microdureza Vickers diferentes.

Palavras-chave: Cimentos de resina, Reprodutibilidade dos testes, Testes de dureza, Polimerização.

\section{ABSTRACT}

Were evaluated the Vickers hardness of 5 artificial resin teeth containing simulated canals and pulp chamber $(17,21,24,33$ and 44$)$ making use of microdurometer. The teeth were placed in metallographic embedded being added phenol-aldehyde heat curing and the effect of temperature and pressure is the fusion of powdered phenolic resin and curing the resin results in the specimen with the embedded tooth. After that, sanded and polished and brought to a stand for fixing the equipment platform at the base of the machine. Next, was performed tests of Vickers hardness (HV) in each of the 5 inlaid teeth making use of microhardness tester equipped with a base indenter with a load of $100 \mathrm{gf}$ that came in 5 randomly chosen points on the tooth surface for 15 seconds. Later readings whose numerical value was calculated on the digital display connected to the microscope.The indentations are left on the sample surface in the form of regular rhombus whose diagonals were measured. There was no statistically significant difference between the mean values of the samples of artificial teeth in polyester resin tested, which means that the average of 5 points for each sample hardships are equivalent $(p>0.05)$, except between teeth $17 \times 21$ and the $17 X 44(p<0.05)$. It was concluded that the average values of the polyester resin artificial teeth showed equivalent Vickers hardness, except between two pairs of samples of artificial teeth that presented different Vickers hardness.

Key-words: Resin Cements, Reproducibility of Results, Hardness Tests, Polymerization.

\footnotetext{
* Professor do Programa de Graduação e Pós-Graduação do Departamento de Odontologia da Universidade de Taubaté E-mail: joaomarcelo.medeiros@ unitau.com.br

** Acadêmica do Departamento de Odontologia da Universidade de Taubaté E-mail: gaabferreira@hotmail.com

*** Professora do Programa de Graduação e Pós-Graduação do Departamento de Odontologia da Universidade de Taubaté E-mail: shabitante@uol.com.br

**** Departamento de Ciência e Tecnologia Aeroespacial-DCTA, Instituto de Aeronáutica e Espaço-IAE/Divisão de Materiais-AMR, São José dos Campos/SP. E-mail: christiancfavd@iae.cta.br

***** Professor Assistente da Disciplina de Periodontia do Curso de Odontologia da Universidade SãoFrancisco- Bragança Paulista. Doutorando em Odontologia pelo Curso de Pós-Graduação da Universidade Cruzeiro do Sul. E-mail:adrianoforghieri@gmail.com

****** Professor Mestre da Disciplina de Endodontia do Curso de Odontologia da Universidade São Francisco- Bragança Paulista. Doutorando em Odontologia pelo Curso de Pós-Graduação da Universidade Cruzeiro do Sul. E-mail: haddadf@usp.br
} 
MEDEIROS JMF

FERREIRA GS

HABITANTE SM

VON DOLLINGER CFA

ROSA LCL

HADDAD FILHO MS

ANÁLISE DA

DUREZA VICKERS

DA SUPERFÍCIE

DE DENTES

ARTIFICIAIS EM RESINA POLIÉSTER

\section{4}

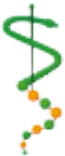

REV, ODONTOL

UNIV, CID, SÃO

PAULO

2014; 26(1): 23

37, JAN-ABR

\section{IN TROD UÇÃO}

Diversos substratos são usados para realizar ensaios com instrumentos endodônticos e dentre eles destacam-se o dente humano, o osso bovino úmido e desidratado, a resina acrílica e fenólica ${ }^{1,2,3,4,5,6}$.

Dentre todas as características dos materiais a dureza é um fator importante a ser observado. Crocoli ${ }^{7}$ (2013) desenvolveu um método de ensaio que ficou Conhecido como ensaio de dureza Vickers. Esse método leva em conta a relação ideal entre o diâmetro da esfera do penetrador Brinell e o diâmetro da calota esférica obtida, e vai além porque utiliza outro tipo de penetrador, que possibilita medir qualquer valor de dureza, incluindo desde os materiais mais duros até os mais moles. Isso não quer dizer que o ensaio Vickers resolva todos os problemas de avaliação de dureza dos materiais. Mas, somado aos outros dois métodos já estudados, é um bom caminho para atender às necessidades de processos industriais cada vez mais exigentes e sofisticados.

A dureza Vickers baseia-se na resistência que o material oferece à penetração de uma pirâmide de diamante de base quadrada e ângulo entre faces de $136^{\circ}$, sob uma determinada carga. $\mathrm{O}$ valor de dureza Vickers (HV) é o quociente da carga aplicada (F) pela área de impressão $(\mathrm{A})$ deixada no corpo ensaiado. Essa relação expressa em linguagem matemática é a seguinte: a máquina que faz o ensaio $\mathrm{Vi}$ ckers não fornece o valor da área de impressão da pirâmide, mas permite obter, por meio de um microscópio acoplado, as medidas de duas diagonais formadas pelos vértices opostos da base da pirâmide. As impressões são extremamente pequenas e, na maioria dos casos, não inutilizam as peças, mesmo as acabadas. O penetrador, por ser de diamante, é praticamente indeformável. Este ensaio aplica-se a materiais de qualquer espessura, e pode também ser usado para medir durezas superficiais ${ }^{8,9}$.

Foram verificadas alterações da medida de microdureza Vickers no esmalte e na dentina de dentes bovinos. Os dentes foram cortados longitudinal e transversalmente. No corte longitudinal avaliou-se a distribuição da dureza em toda a extensão da coroa e no corte transversal foi possível avaliar a homogeneidade da dureza ao longo da secção do dente. A medição da dureza foi realizada com microdurômetro Shimadzu num total de 10 medições em cada amostra, sendo cinco na região da dentina e cinco na região do esmalte. Os resultados mostraram variações nessas propriedades, em função do meio e do tempo, o que comprova a necessidade do controle do armazenamento de dentes extraídos, de modo a se obterem resultados confiáveis em pesquisas que os utilizam ${ }^{10}$.

Foi avaliada a capacidade de absorção de choque de 7 dentes posteriores artificiais de resina composta, um de resina acrílica e um dente de porcelana por ensaio de queda livre de bola com um acelerômetro bem como avaliação superficial da dureza Vickers. Estes foram imersos em água destilada a $37^{\circ} \mathrm{C} / 50$ horas. Os dentes de resina composta mostraram um valor de impacto intermediário entre o dente resina acrílica e o dente de porcelana. Entre os dentes artificiais investigados, o de porcelana mostrou o valor mais alto de impacto. Foi observada uma diferença significativa no valor de impacto entre o dente de porcelana e resina composta e os dentes de resina acrílica. No entanto, não foi observada diferença significativa entre os dentes de resina composta testados. Foi encontrada correlação significativa entre os valores de impacto e a dureza Vickers ${ }^{11}$.

Realizou-se pesquisa para avaliar a microdureza superficial de 4 resinas compostas micro-híbridas de cor extraclara quando fotopolimerizadas com duas fontes de luz: halógena e de LEDs. Concluiu-se que a cor extraclara obteve os menores valores de microdureza independentemente do tipo de fonte de luz utilizada e o aparelho à base de LEDs proporcionou os valores mais baixos de microdureza superficial ${ }^{12}$.

Efetuaram-se as análises do número de fraturas de limas do sistema rotatório ProTaper em blocos de canais simulados de resina acrílica transparente com 40 graus de curvatura e comprimento real de trabalho de 19 milímetros. Inicialmente, o instrumento S1 serviu para modelar o terço cervical e médio do canal e, após isso, valeu-se do instrumento SX para acesso reto, seguido pelas limas manuais $n^{\circ} 10$ 
e 15 no comprimento real de trabalho e, por último, utilizaram-se limas S1 e S2 no comprimento de trabalho para o acabamento sendo os últimos três instrumentos F1, F2 e F3 no comprimento real de trabaIho realizando o batente apical, todas elas acionadas com motor Endo-Plus (Driller) a velocidade rotacional de 350rpm e, como substância química auxiliar, solução de hipoclorito de sódio a 0,5\%. Concluiu-se que o uso de limas ProTaper em canais curvos mostrou-se mais seguro até o quarto uso, sendo que a fratura poderá ocorrer no ponto de maior angulação da curvatura e quando não há interferências cervicais e que as limas que mais fraturaram foram as de maiores conicidades, as " $F$ "13.

A resistência à abrasão foi avaliada in vitro em relação à microdureza superficial e à estabilidade de cor de dentes artificiais de resina acrílica. Foram utilizados 12 pré-molares superiores artificiais em resina. Para a análise da microdureza superficial Vickers foram utilizados 6 incisivos laterais superiores. Concluiu-se que o grupo Biolux, seguido do Antaris, Ivostar e Biocler apresentam maiores valores de microdureza ${ }^{14}$.

Avaliou-se in vitro a microdureza de novos compósitos em diferentes espessuras. Foram confeccionados 20 corpos de prova avaliados neste estudo: Z 250, 3M - híbrida, Clearfil Majesty, Kuraray - micro-híbrida, Epricord, Kuraray - híbrida, Natural Look, DFL, micro-híbrida, sendo que para cada grupo de resina composta foram confeccionados 4 corpos de prova em diferentes espessuras: 1, 2, 3 e 4mm. A fotoativação foi aplicada com luz halógena, utilizando-se aparelho fotopolimerizador com intensidade de $500 \mathrm{~mW} / \mathrm{cm} 2$ por 40 segundos. Após a polimerização, os corpos de prova foram armazenados em estufa a $37^{\circ} \mathrm{C}$, a seco, por uma semana, em recipientes escuros. A microdureza $\mathrm{Vi}$ ckers foi avaliada por meio de um microdurômetro digital HMV (Shimatzu, Japão), com auxílio do software CAM-Wins, utilizando-se carga de 50gf por 45segundos e 5 medidas foram obtidas por corpo de prova. Concluiu-se que os valores de microdureza diminuíram com o aumento da espessura da resina composta, para todas as resinas utilizadas ${ }^{15}$.
Foi realizado estudo da resina acrílica de dentes artificiais com dureza padronizada. Os dentes artificiais em acrílico ainda estão entre os dentes artificiais mais frequentemente utilizados. Essas marcas não dão quaisquer dados de propriedades mecânicas, incluindo-se dados de dureza. A ADA, especificação padrão $n^{\circ} 15$, exige dureza mínima para o acrílico de dentes artificiais. A partir de cada marca, 4 dentes foram sorteados e receberam 10 escores superiores e inferiores. Concluiu-se que as cinco marcas de dentes artificiais em acrílico estão dentro da especificação $\mathrm{n}^{\circ} 15$ da ADA, não havendo diferença de valores de dureza entre as cinco marcas ${ }^{16}$.

Foi feita revisão da literatura a respeito dos efeitos da solução de hipoclorito de sódio nas propriedades mecânicas da dentina do canal radicular quando a mesma é utilizada durante o tratamento endodôntico e também se verificaram os efeitos de diferentes substâncias químicas auxiliares (soro fisiológico, hipoclorito de sódio, clorexidina gel, peróxido de ureia - Endo-PTC $($ e EDTA) na microdureza Vickers e morfologia observadas por meio de análise em microscopia eletrônica de varredura da dentina da câmara pulpar de dentes anteriores decíduos e permanentes. O uso de substâncias químicas auxiliares diminuiu os valores de microdureza dentinária Vickers tanto para dentes decíduos quanto para os permanentes. Observaram-se resultados não conclusivos com o uso do EDTA a $17 \%$ na dentina da câmara pulpar dos dentes decíduos e permanentes, uma vez que a microdureza superficial não pôde ser mensurada. Concluiu-se que a solução de hipoclorito de sódio a $1 \%$ e 5,25\% produziu os menores valores de microdureza Vickers para dentes decíduos e permanentes se comparados à clorexidina gel a $2 \%{ }^{17}$.

Analisou-se o efeito dos agentes clareadores na microdureza de uma resina composta nanoparticulada. Foram confeccionados 28 corpos de prova com a resina composta fotopolimerizável nanoparticulada FiltekTM Supreme XT para esmalte na cor A3E e a microdureza Vickers inicial foi mensurada (carga de 50gf em 30 segundos) na superfície de topo dos corpos de prova. Os grupos divididos: G1)
MEDEIROS JMF

FERREIRA GS

HABITANTE SM

VON DOLLINGER CFA

ROSA LCL

HADDAD FILHO MS

ANÁLISE DA

DUREZA VICKERS

DA SUPERFÍCIE

DE DENTES

ARTIFICIAIS

EM RESINA

POLIÉSTER
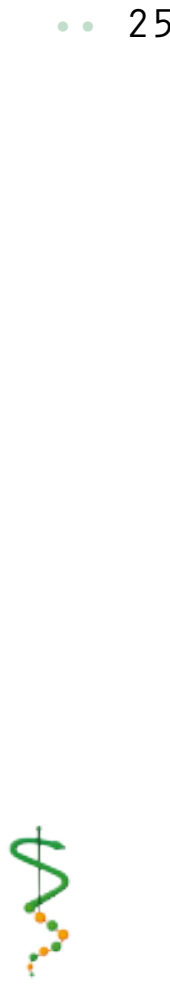

ReV. OdOntOl.

UnIV. CID. São

Paulo

$2014 ; 26(1): 23-$

37, JAN-ABR 
MEDEIROS JMF

FERREIRA GS

HABITANTE SM

VON DOLLINGER CFA

ROSA LCL

HADDAD FILHO MS

ANÁLISE DA

DUREZA VICKERS

DA SUPERFÍCIE

DE DENTES

ARTIFICIAIS EM :

RESINA POLIÉSTER
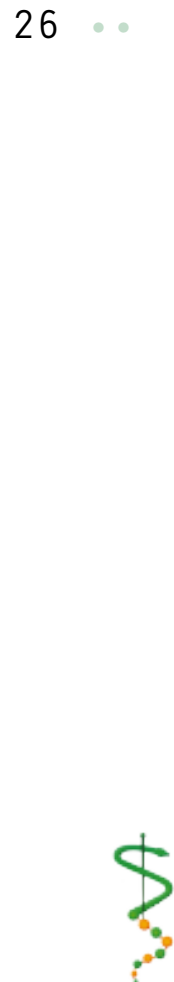

REV, ODONTOL ,

UNIV, CID. SÃO

PAULO

$2014 ; 26(1): 23-$

37, JAN-ABR saliva artificial (21 dias - controle); G2) gel de peróxido de hidrogênio a $7 \%$ aplicado por 4h/dia, durante 14 dias; G3) peróxido de carbamida a $10 \%$ por $4 \mathrm{~h} /$ dia, durante 14 dias: G4) gel de peróxido de hidrogênio 35\% aplicado em três sessões de 30 minutos cada, com intervalo entre sessões de uma semana (21 dias); e G5) peróxido de carbamida a $35 \%$, três sessões de 30 minutos cada, com intervalo entre sessões de uma semana (21 dias). As superfícies de topo dos corpos de prova receberam os tratamentos e foram submetidas ao teste de microdureza Vickers. A aplicação dos agentes clareadores não alterou a microdureza das resinas compostas. Portanto, ficou concluído que não há necessidade de troca das restaurações após o clareamento $^{18}$.

Estabeleceram-se as alterações da microdureza Vickers da dentina adjacente ao canal radicular de raízes de 105 dentes incisivos bovinos tratados endodonticamente, utilizando-se como solução irrigadora o hipoclorito de sódio a 2,5 e 5,0\%, associado ou não ao ácido cítrico a $10 \%$ e ao vinagre de maçã. Dividiram-se as amostras em 21 grupos de 5 raízes cada $(n=5)$, de acordo com a substância e o regime de irrigação, assim como o tempo de irrigação. Realizou-se o preparo, usando-se limas ProFile. Para análise da microdureza Vickers foi usado microdurômetro (Futuretech FM 700), tomando-se medidas em três pontos, a saber: o mais próximo possível da luz do canal, 50 milímetros de distância da primeira do ponto da primeira medida em direção ao cemento e o terceiro distando 100 milímetros do ponto da primeira medida tomada nos três terços da raiz: cervical, médio e apical. Tanto para os regimes de irrigação quanto para os terços da raiz dos dentes não ocorreu significado estatístico; no entanto, entre os locais de medida a dentina adjacente ao lúmen do canal é menos dura do que a dentina próxima ao cemento com significado estatístico ${ }^{19}$.

Foram examinados os efeitos dos clareadores na estrutura dental e selecionados 90 dentes para preparo de 6 grupos de 15 dentes humanos cada, sendo essas amostras submetidas a testes de microdureza Vickers. Após, utilizaram-se 6 tipos diferentes de clareadores usados em consultório ou pelo paciente. Os resultados obtidos mostraram que, se forem considerados os valores médios das microdurezas antes e após a última sessão de clareamento submetida aos clareadores utilizados em consultório, observou-se diminuição de aproximadamente $2 \%$ na microdureza. Nos clareadores caseiros, a diminuição na microdureza foi de aproximadamente $24 \%$. Concluiu-se que o uso indiscriminado desses tipos de clareadores pode provocar danos à estrutura dos dentes ${ }^{20}$.

Foi estudado o clareamento dental caseiro com Whiteness Perfect a $10 \%$ (FGM) em vinte terceiros molares, sendo cada dente seccionado transversalmente, eliminando-se a porção radicular e, longitudinalmente, sendo dividido em quatro fragmentos, totalizando setenta e cinco corpos de prova que foram sorteados aleatoriamente e divididos em cinco grupos de 15 espécimes. No teste de microdureza, as amostras foram incluídas em resina de poliéster para realização das medidas de dureza Vickers efetuadas no microdurômetro digital (Microhardness tester FM, da Future Tech), com penetrador de base piramidal e quadrada. As endentações foram feitas sobre a superfície de esmalte, usando-se uma carga estática de 50 gf por 10 segundos. O clareamento com peróxido de carbamida a $10 \%$ não mostrou diferença estatística significativa em relação à dureza do esmalte, ao clareamento e à remineralização com flúor a 1,23\%; apresentou diferença estatística significativa em termos de dureza. Concluiu-se que o clareamento dental caseiro com peróxido de carbamida a $10 \%$ pode trazer benefícios estéticos aos pacientes, sem acarretar prejuízos estruturais ao esmalte dental hígido, mesmo na ausência de remineralização com flúor ${ }^{21}$.

Considerou-se a ação das soluções quelantes sobre a microdureza da dentina radicular de 5 incisivos centrais humanos, sendo quatro corpos-de-prova para cada raiz. Cada dente recebeu, por meio de uma micropipeta automática, $50 \mu \mathrm{l}$ da solução a ser testada, a saber: EDTA 17\% (Biodinâmica, Quím. e Farm., Ibiporã-PR, Brasil), CDTA 17\% (SIGMA Chemical CO., St.Louis, USA) e EGTA 17\% (SIGMA 
Chemical CO., St. Louis, USA). As amostras foram levados ao aparelho de medição da microdureza Vickers (Wolpert 121, Ludwigshafen, Alemanha), utilizando-se carga de 50gf por 15 segundos. Todas as soluções testadas foram estatisticamente diferentes entre si $(p<0.05)$ e as soluções quelantes testadas foram efetivas quanto à redução da microdureza dentinária ${ }^{22}$.

Julgou-se a microdureza de duas resinas compostas, usando-se duas fontes de luz, uma halógena e outra à base de diodo emissor de luz (LED). Confeccionaram-se quarenta corpos de prova, sendo vinte com Tetric Ceram e vinte com Tetric Flow, ambos fotoativados com um apareIho de luz halógena e com diodo emissor de luz (LED). Foi feita a análise dos valores de microdureza Vickers, nas regiões de topo e base dos corpos de prova, utilizando-se microdurômetro, com penetrador tipo Vickers, com carga estática de 50 gramas, durante 10 segundos. Os resultados mostraram que a fonte de luz halógena foi estatisticamente mais efetiva $(p<0,05)$ que o LED na microdureza superficial e, quando comparados os tipos de resinas compostas, a Tetric Ceram apresentou valores de microdureza estatisticamente maiores $(p<0,05)$ que a Tetric Flow, sendo as regiões de topo com microdureza maior $(p<0,05)$ em relação às regiões de base, independente da fonte de luz e do material resinoso utilizado, sendo a fonte de luz halógena mais eficaz que a LED ${ }^{23}$.

Foi feita avaliação da degradação hidrolítica, testando-se a dureza superficial de quatro compósitos com diferentes tipos de carga, após estocagem por seis meses em água destilada. Amostras com 7 milímetros de diâmetro e 3 milímetros de altura foram confeccionadas em dois incrementos, utilizando-se aparelho de luz halógena com $600 \mathrm{mV} / \mathrm{cm}^{2}$ por 40 segundos $(n=3)$. As amostras foram submetidas ao teste de dureza Vickers com carga de 50gf durante 15 segundos, realizando-se 4 endentações por amostra após armazenamento em água destilada, sob o abrigo da luz, por $24 \mathrm{~h}$ a $37^{\circ} \mathrm{C}(\mathrm{G} 1 \mathrm{~A}$ a G4A) e foi obtida a primeira análise da microdureza e após 6 meses, a $37^{\circ} \mathrm{C}(\mathrm{G} 1 \mathrm{~B}$ a G4B), as mesmas amostras foram novamente submetidas ao teste. Quatro resinas compostas foram utilizadas, com partículas de carga de diferentes tamanhos: G1 (Z250 - 3M/ESPE) que utiliza partículas híbridas; G2 (Z350 - 3M/ESPE) que possui nanopartículas; G3 (Brilliant - Coltene) e G4 (Esthet- X - Dentsply), que contêm na composição partículas nano-híbridas. Três corpos de prova de cada compósito $(n=12)$ foram confeccionados e submetidos a meio contendo água destilada. Fotopolimerizador optilight com intensidade de $600 \mathrm{mw} / \mathrm{cm}^{2}$ para a polimerização do compósito e finalização da amostra, recipientes plásticos para armazenamento dos corpos de prova. Concluiu-se que os compósitos Z250 - 3M ESPE e Z350 - 3M ESPE apresentaram o melhor desempenho. Os resultados das resinas Z250 e Z350 apresentaram maiores valores, seguidas das resinas Esthet-X e Brilliant. Após 6 meses de armazenamento apenas os compósitos Brilhant e Z350 apresentaram diminuição nos valores de dureza superficial ${ }^{24}$.

Objetivou-se avaliar in vitro a microdureza do esmalte dentário após a exposição em bebidas isotônicas, sendo Gatorade de tangerina e de limão. Foram confeccionados 25 corpos de provas de esmalte, sendo 15 pré-molares humanos extraídos e 10 terceiros molares. Procedeu-se à análise da microdureza Vickers nas 25 faces de esmalte antes e após a imersão dos corpos de prova nas soluções. Os testes foram realizados por um período de um minuto, seguido de três minutos na saliva artificial. Esse ciclo repetiu-se cinco vezes, totalizando 20 minutos, sendo feito duas vezes ao dia, durante três dias consecutivos e com um intervalo de 12 horas entre eles. Ao final do sexto teste, foram feitas novamente mensurações da microdureza por meio da aplicação de uma carga de 100 gramas durante 15 segundos. A análise da microdureza Vickers nos tempos antes e após a imersão mostrou significado estatístico antes e após a imersão dos corpos de prova nas bebidas. As bebidas analisadas ocasionaram desmineralização do esmalte dentário permanente, com significado estatístico entre os valores iniciais e finais da microdureza, os quais foram submetidos aos ensaios com as bebidas ${ }^{5}$.

Considerou-se a perda de corte do instrumento rotatório ProTaper em função do
MEDEIROS JMF FERREIRA GS HABITANTE SM

VON DOLLINGER CFA ROSA LCL

HADDAD FILHO MS

ANÁLISE DA

DUREZA VICKERS

DA SUPERFÍCIE

DE DENTES

ARTIFICIAIS

EM RESINA

POLIÉSTER
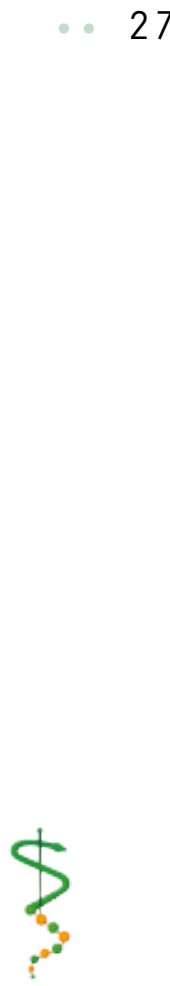

REV. OdONTOL.

UNIV. CID, SÃo

Paulo

2014; 26(1): 23 -

37, JAN-ABR 
MEDEIROS JMF

FERREIRA GS

HABITANTE SM

VON DOLLINGER CFA

ROSA LCL

HADDAD FILHO MS

ANÁLISE DA

DUREZA VICKERS

DA SUPERFÍCIE

DE DENTES

ARTIFICIAIS EM: RESINA POLIÉSTER número de uso e esterilização em autoclave. Foram utilizados 10 blocos de canais simulados de dentes artificiais de resina transparente com ângulo de curvatura de 45 graus. Foi feita a pesagem inicial e, a seguir, preparo com motor elétrico Endo Pro-torque, padronizando-se o tempo de cada instrumento em 3 minutos. Após isso, o bloco foi lavado com detergente neutro, seco com gaze, canal aspirado e seco com cone de papel absorvente, pesando-se e anotando o peso final. A cada uso as limas rotatórias eram limpas com gaze embebida em álcool, lavadas com detergente neutro e secas também com gaze e levadas em envelope descartável para processo de esterilização em autoclave com ciclo de 20 minutos. Os instrumentos utilizados perderam a sua capacidade de corte em função do número de uso. A partir do sétimo uso, a lima ProTaper perdeu consideravelmente sua efetividade, recomendando-se seu descarte ${ }^{6}$.

O propósito deste estudo foi avaliar a microdureza Vickers da superfície de dentes artificiais pedagógicos de resina poliéster utilizados em endodontia, valendo-se de microdurômetro.

\section{MATERIAIS E MÉTODOS}

Foram escolhidos aleatoriamente 5 dentes artificiais pedagógicos (Figura 1) de resina de poliéster com canais artificiais e câmara pulpar (IM do Brasil Indús-

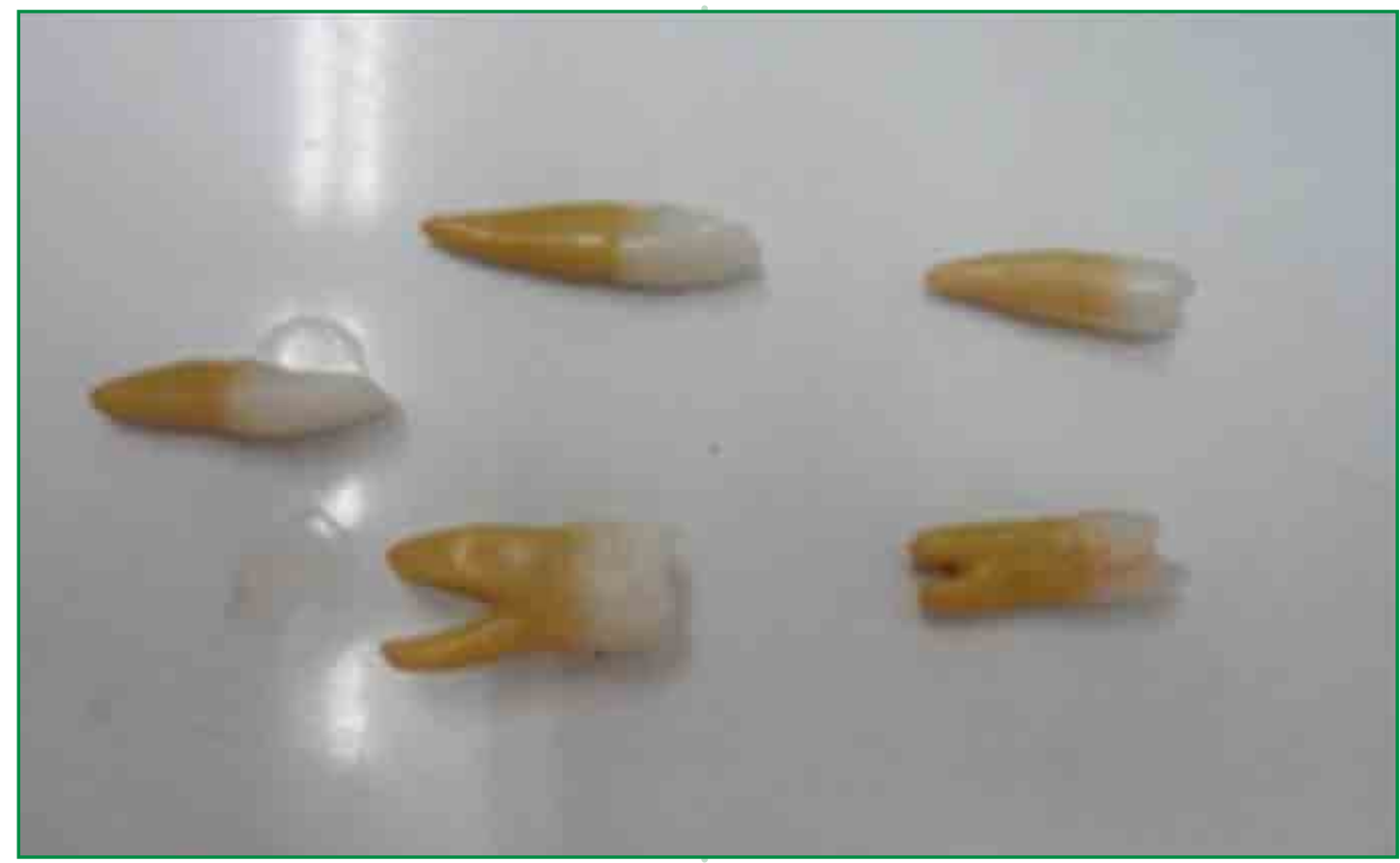

Figura 1 - Dentes artificiais

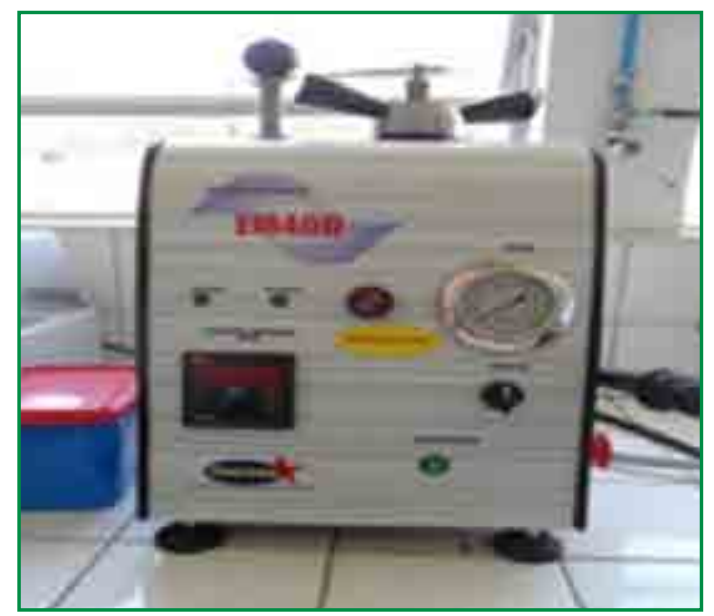

Figura 2 - Máquina embutidora metalográfica tria e Comércio de Produtos Odontológicos Ltda/São Paulo/SP). As superfícies dos elementos artificiais 17, 21, 24, 33 e 44 foram analisadas quanto à dureza Vickers no Departamento de Ciência e Tecnologia Aeroespacial-DCTA, no Instituto de Aeronáutica e Espaço-IAE/Divisão de Materiais-AMR, em São José dos Campos/SP.

Os dentes foram acondicionados um a um em uma embutidora metalográfica, modelo EM40D (Teclago Tecnologia em Máquinas Metalográficas/Vargem Grande Paulista/SP) (Figura 2). O referido equipamento possui sistema hidráulico de pres- 


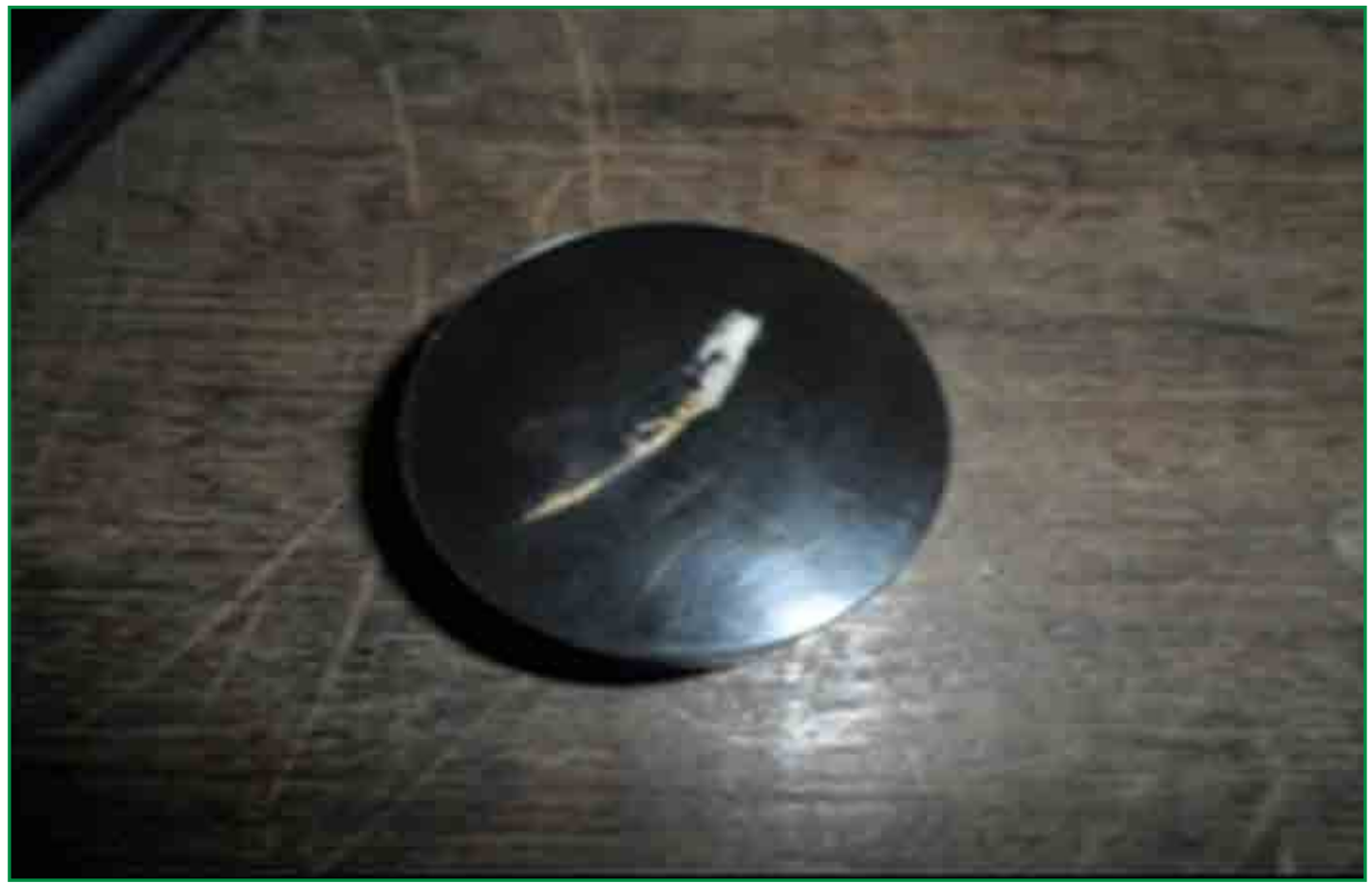

MEDEIROS JMF

FERREIRA GS

HABITANTE SM

VON DOLLINGER CFA

ROSA LCL

HADDAD FILHO MS

ANÁLISE DA

DUREZA VICKERS

DA SUPERFÍCIE

DE DENTES

ARTIFICIAIS

EM RESINA

POLIÉSTER

Figura 3 - Dente embutido antes de sofrer polimento

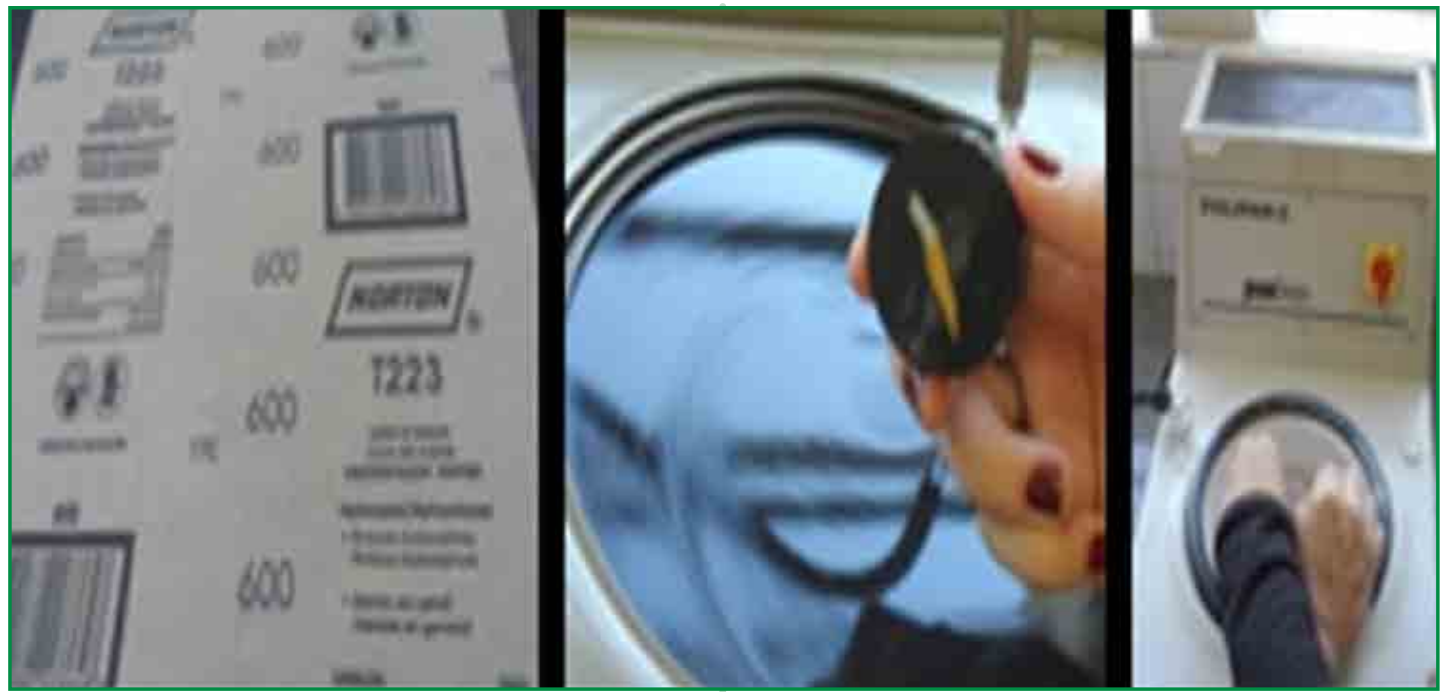

Figura 4 - Dente artificial sendo polido com lixa e pasta na máquina politriz Polipan 2

são acionado manualmente através de alavanca lateral (Figura 2), manômetro e alarme sonoro luminoso.

Cada dente foi acondicionado nessa embutidora onde inicialmente adicionou-se resina fenol-aldeído de cura a quente que por efeito de temperatura e pressão sobrevém à fusão do pó de resina fenólica e a cura da resina, do que resulta corpo de prova com o dente embutido (Figura 3).

Cada corpo de prova foi lixado em lixadeiras com granulometria 120, 240, 400 e 600 mesh de pratos duplos marca struers, modelo Knuth rotor 2, concomitantemen- te com lubrificação de água corrente, para resfriamento dos corpos de prova e remoção dos resíduos de material retirados pelas lixas e, após isso, foram lavados em água corrente.

Depois os corpos de prova foram polidos em politriz de parto rotativo Polipan-2 (Figura 4) (Panambra Zwick Roell/São Bernardo do Campo/SP) com pasta de diamante de granulometrias $3 \mu \mathrm{m}$ e, depois, $1 \mu \mathrm{m}$. Entre cada etapa de polimento os corpos de prova foram lavados em água corrente (Figura 5).

Foram feitos os ensaios da dureza $\mathrm{Vi}_{\text {- }}$ $\because 29 \cdots$

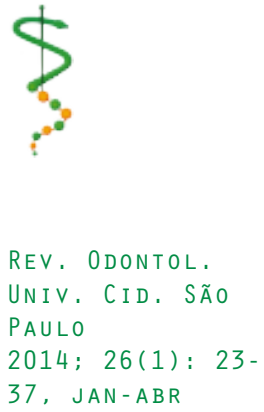


MEDEIROS JMF

FERREIRA GS

HABITANTE SM

VON DOLLINGER CFA

ROSA LCL

HADDAD FILHO MS

ANÁLISE DA

DUREZA VICKERS

DA SUPERFÍCIE

DE DENTES

ARTIFICIAIS EM RESINA POLIÉSTER

30

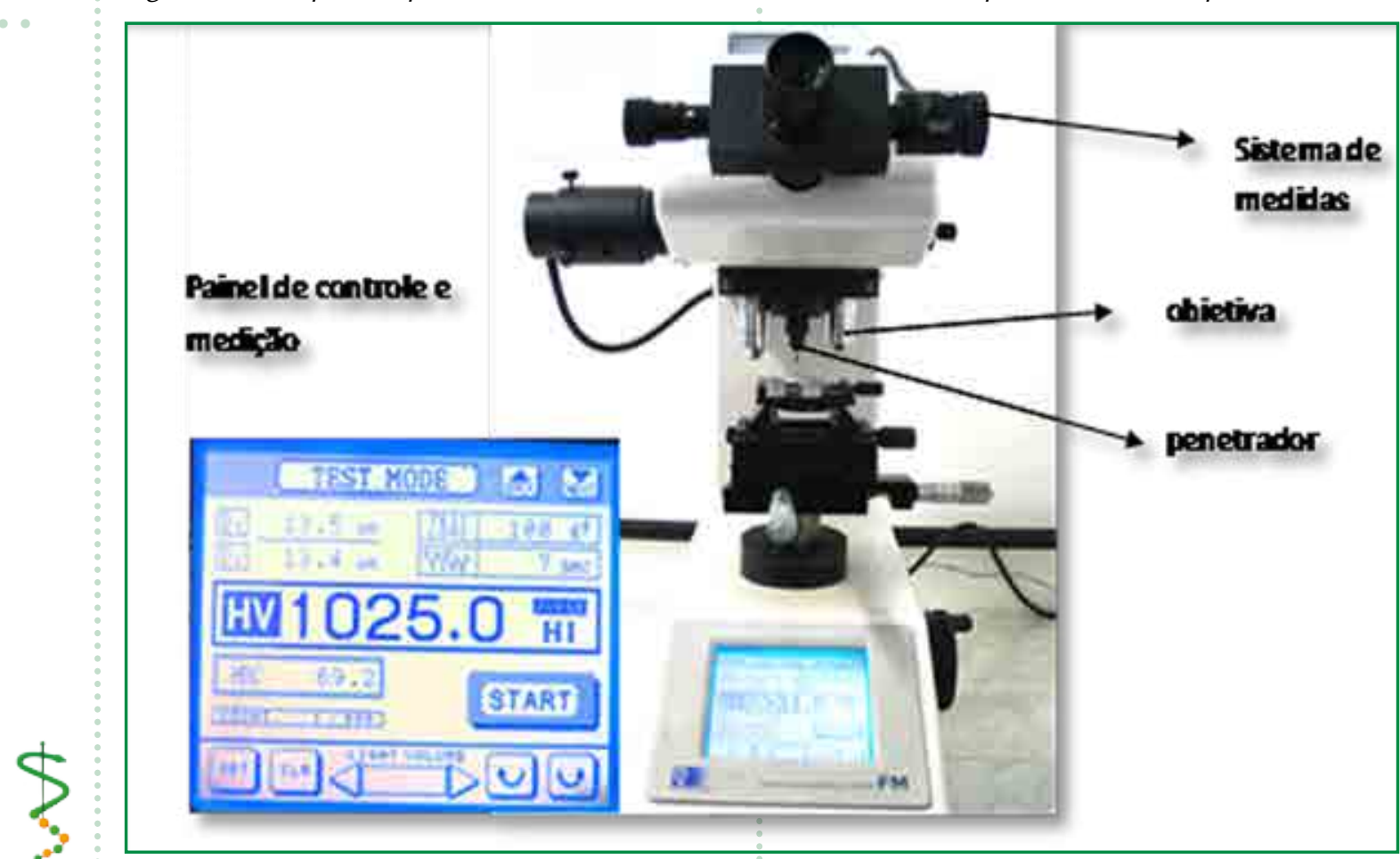

Figura 6. Microdurômetro Futuretech FM7

ckers (HV) nos 5 dentes embutidos, uti- butidos na baquelita foram levados a um lizando-se microdurômetro Futuretech modelo FM - 7 (Figura 6).

As amostras dos dentes artificiais emsuporte para fixação em uma plataforma na base do equipamento, realizando-se os ensaios com visualização por meio de

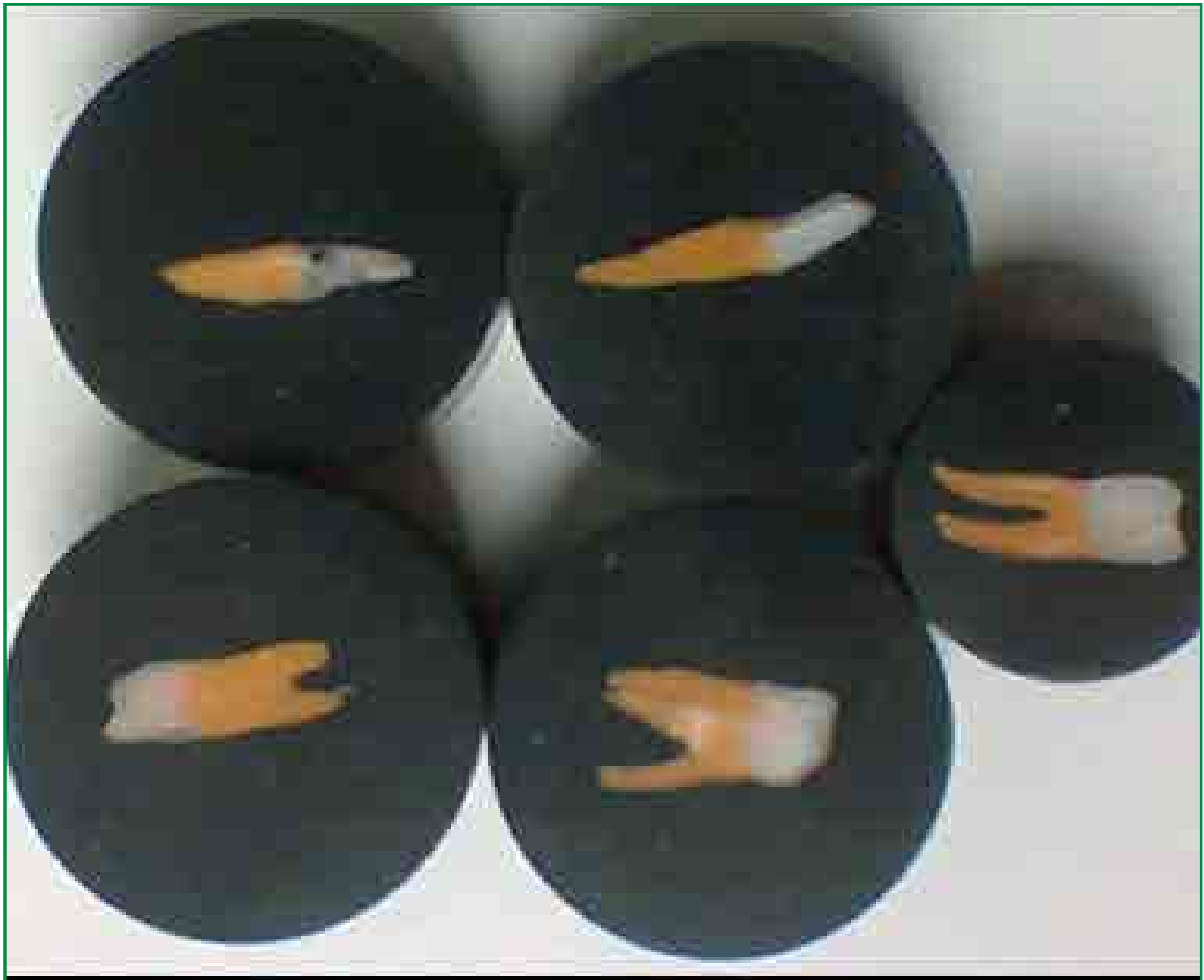

Figura 5 - Corpos de prova com os dentes artificiais embutidos após lixamento e polimento.
REV, ODONTOL UNIV, CID, SÃ

37, JAN-ABR 


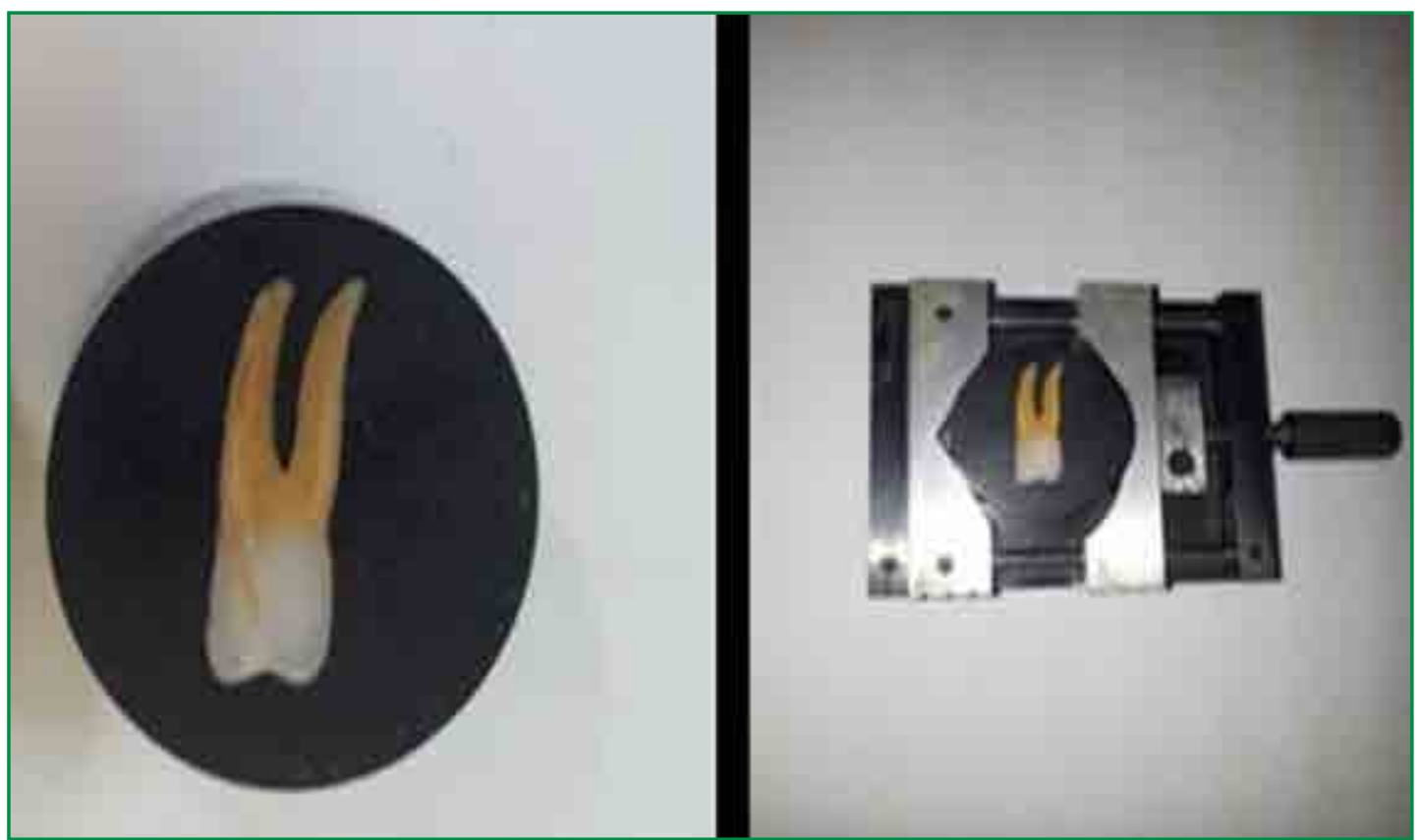

Figura 7 - Dente artificial montado no suporte e levado ao microscópio para leitura

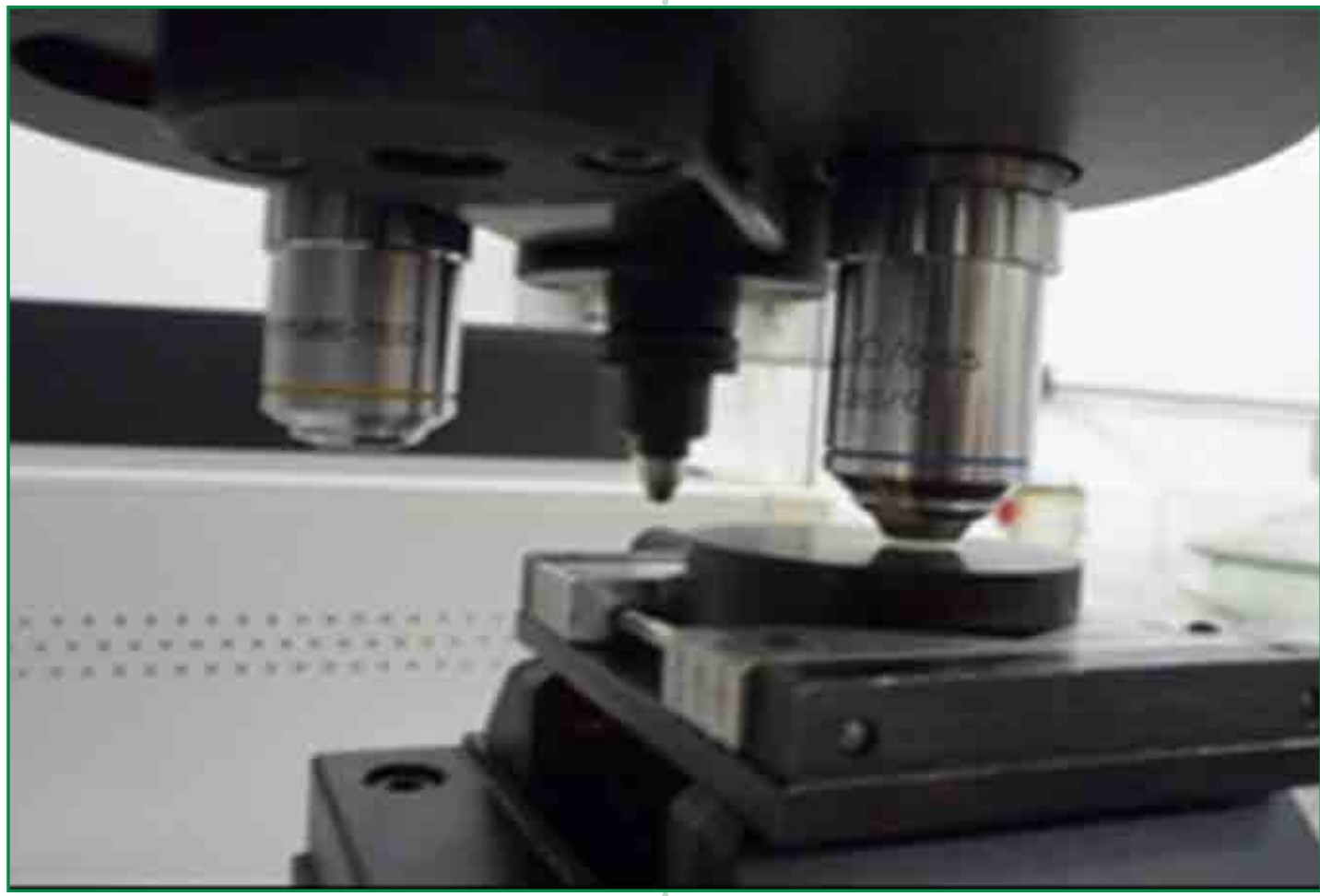

Figura 8 - Penetrador e lentes de aumento para determinação da microdureza

imagens obtidas do microscópio e, através de visor digital, observavam-se os valores determinados das medidas obtidas de cada ponto de cada dente artificial em particular (Figura 7).

Por meio da lente objetiva de 10X foi ajustada a altura da amostra, no ponto onde a imagem ficou em foco. Um ajuste fino da posição foi realizado com a objetiva de 50X (Figura 8). Para os procedimen- tos de leitura das amostras foi aplicada uma carga de 100gf com um penetrador bastante duro talhado em diamante com forma de uma pirâmide quadrangular com ângulo de diedro de $136^{\circ}$, o qual entra em contato com as 5 superfícies do material a ser examinado durante 15 segundos (Figura 9). As extensões da marca de penetração chamadas endentação são deixadas na superfície da amostra sob a forma de
MEDEIROS JMF

FERREIRA GS

HABITANTE SM

VON DOLLINGER CFA

ROSA LCL

HADDAD FILHO MS

ANÁLISE DA

DUREZA VICKERS

DA SUPERFÍCIE

DE DENTES

ARTIFICIAIS

EM RESINA

POLIÉSTER

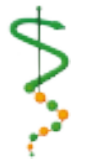

REV. ODONTOL.

UNIV, CID . SÃO PAULO

$2014 ; 26(1): 23$ -

37 , JAN-ABR 
MEDEIROS JMF

FERREIRA GS

HABITANTE SM

VON DOLLINGER CFA

ROSA LCL

HADDAD FILHO MS

ANÁLISE DA

DUREZA VICKERS

DA SUPERFÍCIE

DE DENTES

ARTIFICIAIS EM RESINA POLIÉSTER

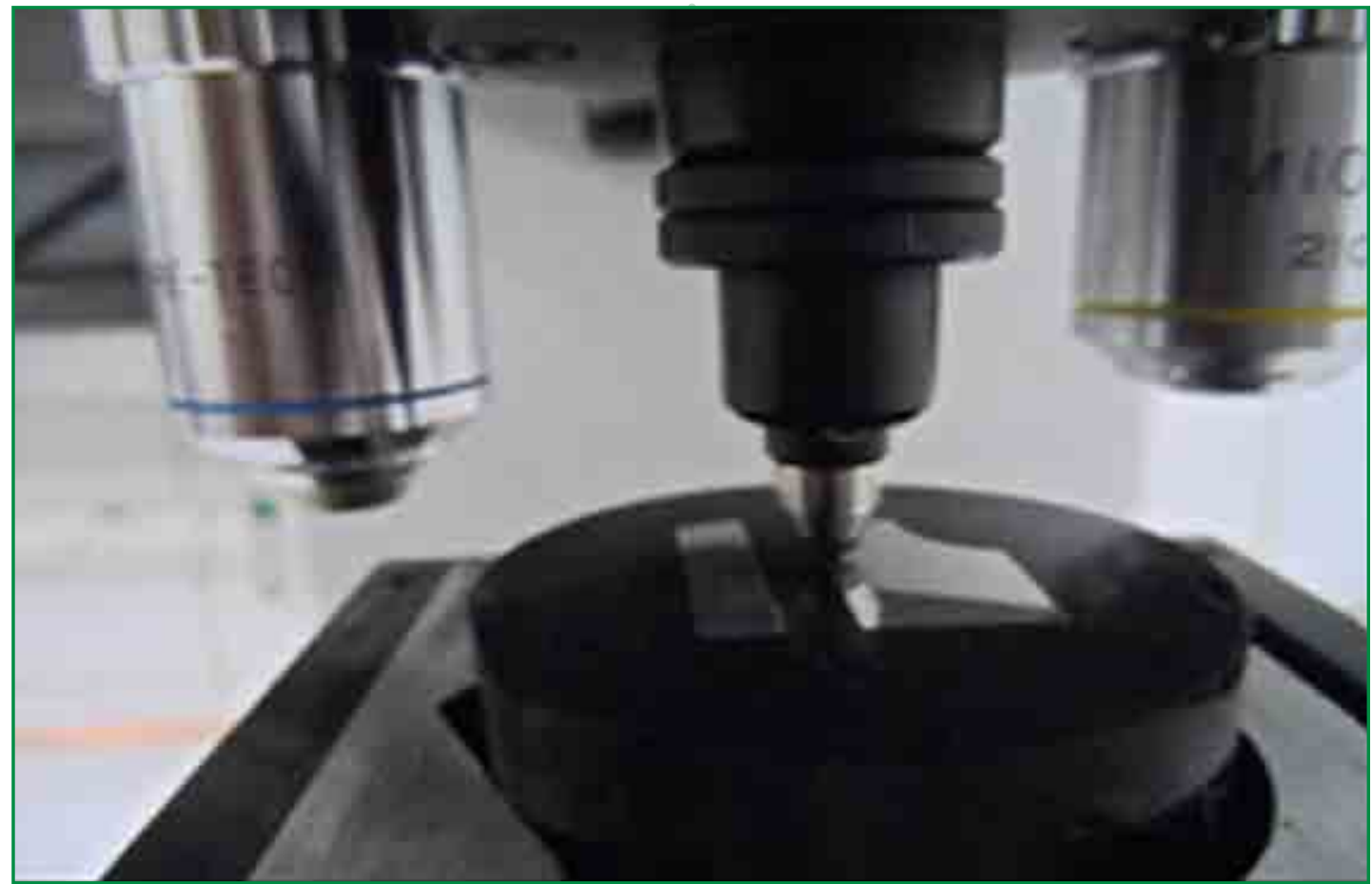

Figura 9. Exemplo da aplicação de carga pelo penetrador no ensaio de microdureza Vickers

losango regular (Figura 10), cujas diagonais são medidas e fica registrada no visor digital no microscópio (Figura 6) a área da superfície impressa pela medição das suas diagonais, matemática e automaticamente calculada por meio de programa no microscópio, conforme esquema da Figura 10 - o valor da dureza Vickers (HV).

Os dados foram tabulados e feita avaliação estatística valendo-se do teste Kolmogorov-Smirnov ao nível de 5\% de significância por meio do Programa BioEstat 5.0 para confrontar a normalidade dos dados.

\section{RESULTADOS}

Os valores da dureza Vickers (HV) de cada amostra estão apresentados na Tabela 1.

Inicialmente, o teste Kolmogorov-Smirnov, ao nível de 5\%, confirmou que os dados de todas as amostras de dentes artificiais de resina poliéster são normalmente distribuídos. Esse comportamento levou a utilizar o teste paramétrico ANOVA: um critério cujo Pvalor $>0,05$ mostrou que não houve significado estatístico entre os valores das médias das amostras dos dentes artificiais em resina testados, o que assegura que, na média dos 5 pontos de cada amostra escolhidos aleatoriamente, 
Tabela 1: Valores da dureza Vickers dos cinco pontos testados em cada dente artificial de resina poliéster, bem como as médias de cada amostra.

\begin{tabular}{lccccc}
\hline \hline & Dente 24 HV & Dente 17 HV & Dente 33 HV & Dente 21 HV & Dente 44 HV \\
\hline 10 ponto & 26,20 & 30,10 & 35,40 & 24,40 & 24,80 \\
20 ponto & 34,30 & 32,70 & 27,30 & 24,00 & 25,30 \\
30 ponto & 33,10 & 29,10 & 24,50 & 24,10 & 24,30 \\
40 ponto & 31,50 & 33,50 & 25,40 & 24,60 & 25,60 \\
50 ponto & 25,30 & 41,30 & 25,90 & 24,20 & 25,10 \\
Média & 30,08 & 33,34 & 27,70 & 24,26 & 25,02 \\
Desvio Padrão & 4,09 & 4,80 & 4,42 & 0,24 & 0,50 \\
Coeficiente de & 13,60 & 14,40 & 16,25 & 0,99 & 2,00 \\
Variação (\%) & & & & \\
\hline \hline
\end{tabular}

as durezas são equivalentes, exceção feita entre as amostras dos dentes $17 \times 21$ e do $17 \times 44$ (Pvalor<0,05), isto é, as durezas são diferentes e com significado estatístico entre as médias das duas amostras, sendo o dente 17 aquele que apresentou média de dureza Vickers maior.

Quanto ao comportamento das medidas determinadas de microdureza Vickers, o coeficiente de variação, conforme a Tabela 1, mostrou uma homogeneidade das amostras dos dentes artificiais de resina poliéster (24, 17, 21 e 44), enquanto a amostra do dente 33 está heterogênea, devido ao ponto medido ser discrepante $(35,40 \mathrm{HV})$ em relação aos outros pontos.

\section{I SCUSSÃO}

Anusavice $^{25}$ (2005) descreve que a resistência, dentre outras propriedades mecânicas, como o limite de proporcionalidade e a ductibilidade, está diretamente relacionada com a dureza superficial de um material.

Define-se ensaio mecânico como a observação do comportamento de um material quando submetido à ação de agentes externos, como esforços e outros. Os ensaios são executados sob condições padronizadas, em geral definidas por normas, de forma que seus resultados sejam significativos para cada material e possam ser facilmente comparados. Dentre os ensaios de materiais, o ensaio de dureza possui importância, pois fornece inúmeras informações sobre o material, o que per- mite trabalhar com maior confiabilidade e obter maior longevidade do mesmo ${ }^{26}$.

O ensaio de dureza é amplamente empregado em pesquisa e avaliação de materiais para controle da qualidade, por ser um método menos oneroso e mais rápido para quantificação de propriedades mecânicas de materiais. Entretanto, os resultados do ensaio estão sujeitos a incertezas como: a força aplicada, as dimensões e geometria do penetrador, o tempo de aplicação de carga e a habilidade do operador, sendo que este último parâmetro representa uma influência significativa no resultado final da medida, o que pode significar fonte de erro. Por essa razão, torna-se importante o desenvolvimento de uma metodologia que não seja influenciada pela capacidade de observação e interpretação do operador ${ }^{27}$.

Por outro lado, alguns autores resolveram automatizar o processo de medição de dureza, eliminando a necessidade da medição da impressão deixada pelo penetrador. Para isso, desenvolveram técnicas de medição da deformação do material durante o ensaio de dureza. Essas técnicas se baseiam em equipamentos que possuem um atuador de força, um sensor de deslocamento e um sensor de carga ${ }^{28}$.

Com vistas à obtenção de maior exatidão nas leituras da microdureza e por entender as diferentes variações numéricas durante o teste mesmo em uma só amostra $^{29,30}$ realiza-se análise em 5 pontos aleatoriamente escolhidos e distintos de
MEDEIROS JMF

FERREIRA GS

HABITANTE SM

VON DOLLINGER CFA

ROSA LCL

HADDAD FILHO MS

ANÁLISE DA

DUREZA VICKERS

DA SUPERFÍCIE

DE DENTES

ARTIFICIAIS

EM RESINA

POLIÉSTER 
MEDEIROS JMF

FERREIRA GS

HABITANTE SM

VON DOLLINGER CFA

ROSA LCL

HADDAD FILHO MS

ANÁLISE DA

DUREZA VICKERS

DA SUPERFÍCIE

DE DENTES

ARTIFICIAIS EM

RESINA POLIÉSTER

\section{4}

REV, ODONTOL

UNIV, CID. SÃO

PAULO

$2014 ; 26(1): 23-$

$37, J A N-A B R$
I SSN 1983-5183

cada amostra, ora em 5 pontos na região da dentina, ora em 5 pontos do esmalte ${ }^{10}$.

Foi feita avaliação da dureza Vickers em 4 pontos na superfície de resinas com carga de $50 \mathrm{~g}$ durante 15 segundos $^{24}$, enquanto que neste presente estudo valeu-se de 100gf durante 15 segundos em 5 pontos aleatórios na superfície de dentes artificiais em resina, o que representa a mesma força e tempo na investigação realizada por outros autores, porém, com 4 endentações em pontos aleatórios ${ }^{5}$.

Mesmo assim, na presente pesquisa os resultados numéricos de HV foram diferentes em cada ponto avaliado das diversas amostras testadas (Tabela 1). Trata-se, portanto, de material heterogêneo em função da presença de microrregiões mais moles e mais duras.

Daí a razão pela qual os valores de microdureza Vickers foram diferentes nos 5 pontos aleatoriamente escolhidos, constituindo as tais incertezas tanto da medida, do material, do equipamento, do operador como também do bloco padrão ${ }^{9}$.

Autores preocuparam-se em encontrar resina acrílica de dentes artificiais com dureza padronizada ${ }^{16}$, muito embora algumas marcas comerciais não apontassem nenhuma informação de propriedades mecânicas, o que inclui, é claro, a microdureza.

Pascon $^{17}$ (2008) foi surpreendido com a diminuição superficial da microdureza Vickers da dentina do canal radicular de dentes humanos decíduos e permanentes em função do uso de substâncias químicas que são usadas durante o preparo do canal radicular, tais como soro fisiológico, hipoclorito de sódio, clorexidina gel,

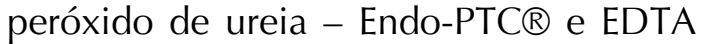
e a mesma ocorrência observada quando se valeu de EDTA, CDTA e EGTA, todos a $17 \%$, na dentina radicular ${ }^{22}$.

Cumpre observar a preocupação de autores com a utilização de dentes artificiais em resina em função dos testes de microdureza Vickers ${ }^{11,12,14,15,17,23,24,31}$, enquanto outros anseiam com a interferência de agentes clareadores, notadamente os caseiros em dentes humanos extraídos, em relação à microdureza Vickers ${ }^{20}$. Ao contrário do que se pensa, o clareamento dental caseiro com peróxido de carbami- da a $10 \%$ pode trazer benefícios estéticos aos pacientes, sem acarretar prejuízos estruturais ao esmalte hígido, mesmo na ausência de remineralização com flúor ${ }^{21}$. Os autores também submeteram ao teste com bebidas isotônicas representadas pelo Gatorade o esmalte de dentes humanos, a fim de observarem a ação do ácido presente nessas bebidas e subsequente análise da dureza Vickers após imersão ${ }^{5}$.

É importante salientar que o uso indiscriminado dessas bebidas poderá acarretar desmineralização do esmalte e provável enfraquecimento da superfície dental e menor dureza.

Cumpre ressaltar que, nos diferentes terços dos canais radiculares de dentes incisivos bovinos, os valores de dureza em função da porosidade são diferentes. No terço cervical, médio e apical, por exemplo, ocorre variação de valores de dureza Vickers, de maneira que em partes da dentina cervical e média os índices são menores do que na região apical, o que traduz uma dentina mais dura nessa região do que na região do terço médio do canal radicular, bem como na região cervical, conforme pesquisa ${ }^{19}$.

$\mathrm{O}$ fato anteriormente citado ocorre com a resina poliéster nos 5 diferentes pontos testados neste estudo, bem como na resina acrílica, cuja dureza foi comprovada com valor em média de 21,10 e, portanto, menos dura do que a baquelita (resina fenólica) ${ }^{1}$ com índice de 39,92 em média, ou seja, microrregiões mais moles e mais duras (Claro, 2004) ${ }^{1}$.

$\mathrm{O}$ referido autor aponta que não ocorre desgaste desse material sugerindo que, graças à sua baixa dureza, deforma-se ao invés de sofrer desgaste ${ }^{1}$. Então há necessidade de substratos mais duros para que ocorra o fenômeno de desgaste e, para tanto, investiga-se mais uma vez, neste presente estudo, a respeito da dureza superficial desses dentes artificiais pedagógicos em resina poliéster com vistas a atender às reais necessidades.

Aliás, o resultado do presente estudo aponta valores médios das amostras em torno de 28,08 HV, enquanto no ensaio realizado por Claro $(2004)^{1}$ o valor da dureza foi menor. Isso significa que a resina usada foi resina acrílica polimetilmetacri- 
lato $^{1}$, enquanto a resina utilizada nesta presente pesquisa é a poliéster.

Ademais, valor máximo de 41,30 HV em uma microrregião do dente artificial 17 denota que, nesse ponto, a dureza foi mais alta, isto é, maior dureza, não só considerando a mesma amostra como também todas as outras, enquanto na microrregião do dente artificial 21 o mínimo valor da dureza obtida foi de $24,0 \mathrm{HV}$, ou seja, microrregião mais mole e com média de HV mais homogênea comparativamente com as outras amostras.

Com vistas a isso, deve-se atentar ao fato de que uma das grandes dificuldades ao escolher um substrato é a obtenção de graus de dureza iguais em toda sua superfície, fato este também observado nesta investigação.

Assim, ocorreram diferenças estatisticamente significantes dos valores médios das microdurezas Vickers apenas nas amostras 17 X 21 e 17 X 44, o que significa que a média dessa amostra é diferente das amostras 21 e 44 . Contrariamente não ocorreu significado estatístico dos valores médios das microdurezas Vickers das demais amostras confrontadas, significando que as médias são semelhantes.

Julga-se que tanto a resina poliéster como a resina acrílica não sejam um substrato preferido para ensaios com instrumentos endodônticos, considerando-se os seus baixos índices de dureza, muito embora a primeira nesta investigação possua índices de dureza maiores que a resina acrílica e, portanto, mais adequada para ensaios com limas.

No entanto, tais referências diferem da resina fenólica com valores de 39,92 $(\mathrm{HV})^{1}$ e, portanto, mais próxima da dentina humana ${ }^{25}$.

O fato de Gênova et al.13 (2004) e Haddad Filho et al.6 (2011) utilizaram canais simulados em resina acrílica com ângulo de 400 e 450 de curvatura, respectivamente, não significa que esse material não represente substrato adequado para testes de ensaio em canais simulados.

A resina acrílica, embora seja menos dura que as resinas poliéster e fenólica, provavelmente permite mais usos durante os ensaios dos instrumentos endodônticos nos canais simulados, fato este observado em recentes investigações ${ }^{6,13}$.

Aliás, em sete vezes de uso, os instrumentos ProTaper em substrato de resina acrílica perdem cerca de $80 \%$ da capacidade de corte, enquanto os mesmos instrumentos usados uma única vez apresentam redução de cerca de $5 \%$ de perda da capacidade de corte $^{6}$. Por outro lado, em média 7 limas fraturam-se entre 4 e 8 usos e 5 limas fraturaram-se entre 1 e 3 usos $^{13}$.

A resina acrílica, apresentando baixa dureza superficial, sofre deformação durante a instrumentação ao invés de se desgastar, ao contrário do que ocorre com a baquelita, que se desgasta e, por conseguinte, perde peso ${ }^{1}$.

\section{CONCLUSÃO}

Parece ser válido concluir que a média dos valores dos dentes artificiais de resina poliéster apresentou microdurezas Vickers equivalentes quando computada a média dos cinco pontos aleatoriamente escolhidos de cada amostra, exceção feita entre dois pares de amostras dos dentes artificiais que apresentaram microdurezas Vickers diferentes.

\section{AGRADEC IMENTOS}

Agradecemos ao Departamento de $\mathrm{Ci}$ ência e Tecnologia Aeroespacial-DCTA, Instituto de Aeronáutica e Espaço-IAE/ Divisão de Materiais-AMR, São José dos Campos/SP e ao Prof. Dr. Christian Frederico de Avila Von Dollinger por todo o auxílio laboratorial a esta investigação.
MEDEIROS JMF FERREIRA GS HABITANTE SM

VON DOLLINGER CFA ROSA LCL

HADDAD FILHO MS

ANÁLISE DA

DUREZA VICKERS

DA SUPERFÍCIE

DE DENTES

ARTIFICIAIS

EM RESINA

POLIÉSTER 
MEDEIROS JMF

FERREIRA GS

HABITANTE SM

VON DOLLINGER CFA

ROSA LCL

HADDAD FILHO MS

ANÁLISE DA

DUREZA VICKERS

DA SUPERFÍCIE

DE DENTES

ARTIFICIAIS EM : RESINA POLIÉSTER
1. Claro FAE. Avaliação do desempenho de limas endodônticas de níquel-titânio após tratamento de superfície [Dissertação]. Taubaté: Departamento de Engenharia Mecânica, Universidade de Taubaté; 2004. 108f.

2. Medeiros JMF, Ishimoto NA, Alkmin ST, Carvalho PL, Risso VA, Zöllner NA. Eficiência de corte de lima de secção triangular usada manualmente e acoplada ao sistema rotatório Endo-Gripper. Publ UEPG Ci Biol Saúde, Ponta Grossa 2006 12(4):41-50.

3. Alves-Claro AP, Claro FA, Uzumaki ET. Wear resistance of nickel-titanium endodontic files after surface treatment. J Mater Sci Mater Med 2008 Oct; 19(10):3273-7.

4. Medeiros JMF, Rodrigues GA, Santos ACM, Rosa LCL, Carvalho PL, Nohara EL. Determinação do comprimento e grau de curvatura em canais radiculares curvos simulados confeccionados em blocos de resina fenólica. Rev Odontol Univ Cid São Paulo 2009 set-dez;21(3):202-11.

5. Xavier C, Cavalcanti A, Montenegro $\mathrm{R}$, Melo J. Avaliação in vitro da microdureza do esmalte dentário após exposição a bebidas isotônicas. Rev Pesq Bras Odontoped Clin Integr 2010 maio-ago;10(2):145-50.

6. Haddad Filho M, Habitante S, Rosa L, Salum G, Almeida E, Medeiros J. Perda de corte da lima protaper quanto a esterilização e número de uso. Rev Odontol Univ Cidade de São Paulo 2011 set-dez;22(3):228-37.

7. Crocoli C. Dureza Vickers (hv). 2013 [Acesso em 11 set. 2013]; Disponível em: http://www.ebah.com.br/content/ ABAAABZUgAC/dureza-vickers-hv.

8. Correa DRN. O teste de dureza Vickers para o estudo de materiais. 2013 [Acesso em 18 de julho de 2012]; Disponível em: http://projetocienciando. blogspot.com.br/2013/05/o-teste-de-dureza-vickers-para-o-estudo.html.
9. ISO 6507-1:2005. Metallic materials: Vickers hardness test: Part 1: Test method. 2005 [Acesso em 11 set. 2013]; Disponível em: http:// www.iso.org/iso/catalogue_detail. htm?csnumber $=37746$.

10. Reis R, Borges P. Variações de propriedades mecânicas em dentes extraídos em função do meio e tempo de armazenamento. In: Congresso Brasileiro de Engenharia e Ciência dos Materiais. São Paulo: Anais. Eng. Elétrica e Informática Industrial Centro Federal de Educação Tecnológica do Paraná; 2000.

11. Kawano F, Ohguri T, Ichikawa T, Mizuno I, Hasegawa A. Shock absorbability and hardness of commercially available denture teeth. Int J Prosthodont 2002 May-Jun;15(3):243-7.

12. Delgado L. Avaliação da microdureza superficial de resinas compostas extraclaras fotopolimerizadas por luz halógenas e LEDs: descrição das características dos aparelhos fotopolimerizadores [Dissertação]. Ponta Grossa: Departamento de Odontologia, Universidade Estadual de Ponta Grossa, Paraná; 2004. 130f.

13. Gênova APS, Antonio MPS, DavidowiCz H, Moura AAM. Avaliação do índice de fraturas das limas ProTaper em canais simulados. Rev Inst Ciênc Saúde 2004 jan-mar;22(1):51-4.

14. Mello PC. Avaliação da resistência à abrasão, microdureza superficial e estabilidade de cor de dentes artificiais de resina acrílica [Dissertação]. Ribeirão Preto: Faculdade de Odontologia de Ribeirão Preto, Universidade de São Paulo; 2007. 109f.

15. Ulson B, Braga S, Sobral M, Turbino $M$, Youssef $M$. Avaliação in vitro da microdureza de novos compósitos em diferentes espessuras. Rev Inst Ciência Saúde 2007 out-dez;25(4):423-9.
REV, ODONTOL.

UNIV, CID, SÃO

PAULO

$2014 ; 26(1): 23$ -

37, JAN-ABR 
16. Dziab H, Hasratiningsih Z, kurnikasari $E$. The hardness of five acrylic artificial teeth brands marketed in Bandung city. Padjadjaran J Dent 2008 Jan;20(1):1922.

17. Pascon F. Influência da irrigação endodontica sobre a microdureza, morfologia e rugosidade de dentes decíduos e permanentes [Tese]. Piracicaba: Departamento de Odontologia, Universidade Estadual de Campinas; 2008. $75 f$.

18. Becker A, Costa S, Rastelli A, Andrade $M$, Bagnato $V$, Bier $C$. Influência dos agentes clareadores na microdureza de resina composta nanoparticulada. Rev Gaúcha Odontol 2009 jan-mar;57(1):27-31.

19. Soria G, Barbin E, Spano J. Avaliação da microdureza de dentes bovinos tratados endodonticamente com diferentes soluções de irrigações. In: XVIII Congresso de Iniciação Científica, XI Encontro de Pós-Graduação e I Mostra Científica da Universidade Federal de Pelotas. Pelotas 2009.

20. Borgonhon A. Análise dos efeitos dos agentes clareadores sobre a estrutura dental [Dissertação]. Curitiba: Departamento de Engenharia Elétrica e Informática Industrial, Universidade Tecnológica Federal do Paraná; 2010. $68 f$.

21. Leandro L, Cesar I, Alves G, Mello J, Rego M, Liporoni P. Avaliação da microdureza do esmalte submetido a remineralização com Naf e ao clareamento dental com peróxido de carbamida $10 \%$. In: X Encontro Latino Americano de Iniciação Científica e VI Encontro Latino Americano de Pós-Graduação. Universidade do Vale do Paraíba; 2013 [Acesso em 25 Set. 2013]; Disponível em: http://www.inicepg.univap.br/cd/INIC_2006/epg/03/ EPG00000172_ok.pdf.

22. Oliveira D, Pedro FLM, Borges ÁH, Neto IM, Pécora JD, Cruz Filho AM. Avaliação do efeito do EDTA, CDTA e EGTA sobre a microdureza da dentina radicular humana. Estudo in vitro. Rev Odontol Brasil Central 2010 19(49):151-4.
23. Santana DP, Carvalho ALP, Pizani AMA, Saraceni CHC, Queiroz CS. Avaliação da microdureza em resinas compostas fotopolimerizadas com sistemas de luz halógena e diodo emissor de Luz. Odontol Clín-Cient 2010 set;9(3):239-42.

24. Silva A. Avaliação do efeito de seis meses de armazenamento em água na superfície de compósito do tipo nanohíbrido, nanoparticulado e híbrido [Monografia]. João Pessoa: Faculdade de Odontologia, Universidade Federal da Paraíba; 2010. 62f.

25. Anusavice KJ. Phillips materiais dentários. Rio de Janeiro: Elsevier; 2005.

26. Tsui TY, Joo Y-C. A new technique to measure through film thickness fracture toughness. Thin Solid Films 2001 401(1-2):203-10.

27. Podchibiakin D. Comparación de diferentes métodos de medición de la impronta de la imagen de microdurómetros. Jornadas Sam Conamet Simposio Materia 2003 1979-82.

28. Hay J, Pharr G. Mechanical Testing and Evaluation. Califórnia: ASM International; 2000.

29. Garcia A, Spim J, Santos C. Ensaio de dureza. In: Ensaios dos materiais. Rio de Janeiro: LTC; 2000. p. 65-89.

30. Vander VJ. Microindentation hardness testing In: Kuhn H, Medlin D. ASM handbook: mechanical testing and evaluation. 10. ed. California: ASM International; 2000.

31. Martins Júnior L. Influência de duas técnicas de ativação complementar de uma resina composta direta/indireta comparadas a uma resina composta laboratorial na resistência ao dobramento e na microdureza Vickers [Dissertação]. Belo Horizonte: Universidade Federal de Minas Gerais, Faculdade de Odontologia; 2006. $118 f$.
MEDEIROS JMF FERREIRA GS HABITANTE SM VON DOLLINGER CFA ROSA LCL

HADDAD FILHO MS

ANÁLISE DA DUREZA VICKERS DA SUPERFÍCIE DE DENTES ARTIFICIAIS EM RESINA POLIÉSTER

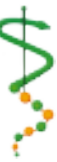

REV. ODONTOL. UNIV. CID, SÃo PAULO $2014 ; 26(1): 23$ 37, JAN-ABR 